\title{
Identification of non-cerebral cyst: Zoonotic Taenia multiceps in domestic goat in Bangladesh
}

\author{
Mohammad Omer Faruk ${ }^{1}$, A. M. A. M. Zonaed Siddiki ${ }^{1}$, Md. Shafiqul Islam ${ }^{1}$, Azizunnesa Rekha², \\ Sharmin Chowdhury ${ }^{1}$, Md. Masuduzzaman ${ }^{1}$ and Mohammad Alamgir Hossain ${ }^{1}$
}

\begin{abstract}
1. Department of Pathology and Parasitology, Faculty of Veterinary Medicine, Chittagong Veterinary and Animal Sciences University, Khulshi 4225, Chittagong, Bangladesh; 2. Department of Medicine and Surgery, Faculty of Veterinary Medicine, Chittagong Veterinary and Animal Sciences University, Khulshi 4225, Chittagong, Bangladesh. Corresponding author: Mohammad Omer Faruk, e-mail: mofaruk05@yahoo.com

Co-authors: AMAMZS: zsiddiki@gmail.com, MSI: si.mamun@ymail.com,AR: msrekha04@yahoo.com, SC: sharminchowdhury77@gmail.com, MM: zamandrmd@yahoo.co.uk, MAH: hossainalamgir54@yahoo.com Received: 29-05-2017, Accepted: 29-08-2017, Published online: 01-10-2017
\end{abstract}

doi: 10.14202/vetworld.2017.1156-1160 How to cite this article: Faruk MO, Siddiki AMAMZ, Islam MS, Rekha A, Chowdhury S, Masuduzzaman M, Hossain MA (2017) Identification of non-cerebral cyst: Zoonotic Taenia multiceps in domestic goat in Bangladesh, Veterinary World, 10(10): 1156-1160.

\begin{abstract}
Aim: This study was performed to identify the non-cerebral Taenia multiceps cyst through molecular phylogeny of the $12 \mathrm{~S}$ rRNA gene.

Materials and Methods: Eight cyst samples were collected from 385 examined slaughtered goats during October 2015-September 2016 from three slaughterhouses in Chittagong City Corporation. Cysts were removed from the thigh muscle, and scolices were collected for light microscopic examination and molecular identification. The DNA was extracted and analyzed by polymerase chain reaction using $12 \mathrm{~S}$ rRNA gene primers. Cyst samples were also preserved in $10 \%$ buffered formalin for histopathological study.
\end{abstract}

Results: T. multiceps non-cerebral cyst is $2.1 \%$ prevalent in goat in this area. Under light microscopic examination, scolex was found with four suckers and a rostellum with the double crown of 32 hooks and hooklets. Molecularly, all the samples were amplified with $12 \mathrm{~S}$ rRNA gene fragments yielded 270 base pair amplicon. Zenker's necrosis with focal to diffuse infiltration of lymphocytes and eosinophil was also found around the cyst wall in histopathological examination.

Conclusion: Although the non-cerebral form of the cysts produced by T. multiceps is genetically identical with the cerebral cyst, previously published data indicated that cerebral T. multiceps cyst is predominant in other parts of the world as well as in Bangladesh. This study showed that non-cerebral cyst is also prevalent in this country which is very important for public health concern. This study depicts an idea of non-cerebral form of zoonotic T. multiceps cyst which will be helpful in taenia cyst control and prevention.

Keywords: 12SrRNA, Bangladesh, goat, non-cerebral cyst, phylogeny, Taenia multiceps.

\section{Introduction}

The cestode Taenia multiceps is a causative agents for coenurosis in sheep and goat affect the central nervous system (CNS) particularly the brain of sheep and goats but rarely in the spinal cord also called Coenurus cerebralis $[1,2]$. Coenurosis is widely recognized as zoonotic parasite [3] and is presents as an endemic condition in small ruminant in Bangladesh [4]. The disease is recorded as $2.4-5.6 \%$ in goat in Bangladesh $[5,6]$. Environmental factors such as rainfall, relative humidity, and air temperature are considered to be the risk factors for coenurosis in this country [7].

Besides this, a lack or limited use of anticestodal drug, uncontrolled backyard slaughtering, and improper offal disposal are also responsible for

Copyright: Faruk, et al. Open Access. This article is distributed under the terms of the Creative Commons Attribution 4.0 International License (http://creativecommons.org/licenses/by/4.0/), which permits unrestricted use, distribution, and reproduction in any medium, provided you give appropriate credit to the original author(s) and the source, provide a link to the Creative Commons license, and indicate if changes were made. The Creative Commons Public Domain Dedication waiver (http://creativecommons.org/ publicdomain/zero/1.0/) applies to the data made available in this article, unless otherwise stated. transmission of this cestode [8]. The cerebral form of the cysts produced by T. multiceps in sheep is genetically identical with the non-cerebral cysts of $T$. multiceps gaigeri $[9,10]$ in intramuscular and/or subcutaneous tissues in goats [11,12]. Recent molecular phylogenetic analysis of nad1, cox1, and $12 \mathrm{~S}$ rRNA showed that $T$. multiceps can cause cerebral coenurosis in sheep and non-cerebral forms in goats but rarely in sheep [13]. Information on intramuscular and subcutaneous (other organs) coenurosis in goats is limited and incomplete. Molecular study of T. multiceps has not been done yet, but Echinococcus granulosus has been identified molecularly in cattle in Bangladesh [14].

The aim of the present study was to determine the prevalence, morphological features of parasite scolex, and molecular detection of T. multiceps besides phylogenetic analysis of the goat isolates sequence with NCBI reference sequences for characterization of cyst in this area.

\section{Materials and Methods}

\section{Ethical approval}

All samples were collected and complies with relevant legislation. It follows the international 
guiding principles for biomedical research involving animals.

\section{Collection of $T$. multiceps cysts}

Eight cyst samples were collected from 385 examined slaughtered goats in three slaughterhouses located in Chittagong City Corporation during October 2015-September 2016. After gross examination cysts were removed from the parasitized organs and preserved in $10 \%$ buffered formalin for histopathological study and the scoleces or larval tissue material from cysts was preserved in $90 \%$ ethanol for molecular study. Scolices were collected through scraping from the sides of germinal layer of the cyst also stained with eosin stain for light microscopic examination.

Genomic DNA extraction and amplification by polymerase chain reaction ( $P C R$ )

Genomic DNA was extracted from protoscolices using iNtRoN Patho gene Spin DNA/RNA Extraction Kit according to the manufacturer's recommendations. Genomic DNA concentrations were determined spectrophotometrically by Qubit 2.0 (Invitrogen, Korea), and the DNA samples were stored at $-20^{\circ} \mathrm{C}$ until used. $12 \mathrm{~S}$ rRNA gene primers were designed according to the mitochondrial genome sequence of $T$. multiceps as follows: Tae-F (5'-GATTCTTTTTAGGGGAAG G-3') and Tae-R (5'-GCGGTGTGTACMTGAGCTAAAC-3'). $50 \mu \mathrm{l}$ of PCR reaction was performed using $10 \mathrm{mM}$ Tris$\mathrm{HCl}, 50 \mathrm{mM} \mathrm{KCl}, 1.5 \mathrm{mM} \mathrm{MgCl}_{2}, 0.2 \mathrm{mM}$ of each deoxynucleotide triphosphate, $20 \mathrm{pmol}$ of each primer, $100 \mathrm{ng}$ template gDNA, and $2 \mathrm{U}$ Taq DNA polymerase (Tokyo, Japan) in each reaction under the following cycling conditions: After an initial denaturation at $94^{\circ} \mathrm{C}$ for $5 \mathrm{~min}$, then $94^{\circ} \mathrm{C}$ for $30 \mathrm{~s}$ (denaturation), $55^{\circ} \mathrm{C}$ for $1 \mathrm{~min}$ (annealing), and $72^{\circ} \mathrm{C}$ for $30 \mathrm{~s}$ (extension) for 35 cycles, followed by a final extension at $72^{\circ} \mathrm{C}$ for $10 \mathrm{~min}$. Samples without genomic DNA were included in each amplification run as negative controls. PCR products were separated on a $1 \%$ agarose gel and detected by ethidium bromide staining.

\section{Sequencing and phylogenetic analysis}

Four PCR products were purified by PCR purification kit (Favor Prep ${ }^{\mathrm{TM}}$ PCR Clean-Up Mini kit, Favorgen Biotech Corporation, www.favorgen.com) according to the manufacturer's instructions, and then, these purified products send to Bioneer, Korea, for sequencing. Sequence chromatograms were analyzed using the Chromas Pro 2 (South Brisbane and Australia) and Mega 6.0 computer software programs [15]. Available reference sequence of T. multiceps was retrieved from NCBI GenBank, and E. granulosus (as outgroup) also inferred from other publications [16]. Sequences were compared with each other using Chromas and BLASTn program. After multiple alignments by ClustalW, phylogenetic analyses of the sequences data were performed using $12 \mathrm{~S}$ rRNA gene sequences, and phylogeny tree was drawn using sequences obtained in this study as well as reference sequences of all described T. multiceps by MEGA6 software.

\section{Histopathology}

Tissue specimens collected from the affected muscular area were fixed in 10\% neutral buffered formalin. The paraffin blocks were prepared, and sections of 4-5 $\mu \mathrm{m}$ thickness were obtained on glass slides with a rotatory microtome. These paraffin sections were stained with hematoxylin and eosin stain for routine histopathology [17].

\section{Results}

In this study, a total of 385 domestic goats were examined during postmortem. Eight animals (2.1\%) were found infected with taeniid cysts with an average diameter of $2.7 \mathrm{~cm}$ (Table-1). The entire cysts were observed in the thigh muscle, inguinal region, and in the prescapular region (Figure-1).

The characteristics morphology of T. multiceps larvae was seen in all of the cysts containing clear fluid with numerous fertile protoscolices. A large number of scolices as white clusters were attached to the internal cyst wall (Figure-2). Under the microscope, larvae or scolex was examined at $10 \times$ magnification (Figure-3). Most of the scolices had four suckers and a rostellum with a double crown of 32 hooks with hooklets (Figure-4).

\section{Histopathological examination of the cyst}

The thin fibrous cyst wall causes mechanical destruction in muscle layer associated with degenerative and necrotic changes including hyaline degeneration and Zenker's necrosis (Figure-5). Diffuse infiltration of lymphocytes and eosinophil was also found around the cyst wall and between muscle fibers (Figure-6).

\section{Molecular study and phylogenetic analysis}

Eight samples were amplified with 12S rRNA gene fragments yielded 270 base pair amplicon (Figure-7). These samples were identified as T. multiceps. Four sequences were submitted to the GenBank under following accession numbers - KX977119, KX977120, KX957746, and KX984366. Phylogenetic tree constructed through using the sequence data indicates that all the isolates from the present study were grouped into a distinct cluster of sheep and goat originated T. multiceps sequences (Figure-8).

Table-1: Occurrence of Taenia spp. cyst.

\begin{tabular}{ccccccc}
\hline Species & $\begin{array}{c}\text { Number of } \\
\text { examined }\end{array}$ & $\begin{array}{c}\text { Number of } \\
\text { infected animal }\end{array}$ & Prevalence \% & $\begin{array}{c}\text { Total number Average diameter } \\
\text { of cyst }\end{array}$ & $\begin{array}{c}\text { Mean or average } \\
\text { of the cyst (cm) }\end{array}$ & $\begin{array}{c}\text { number of cyst/animal } \\
\text { number }\end{array}$ \\
\hline Goat & 385 & 8 & 2.1 & 42 & 2.7 & 5.25 \\
\hline
\end{tabular}




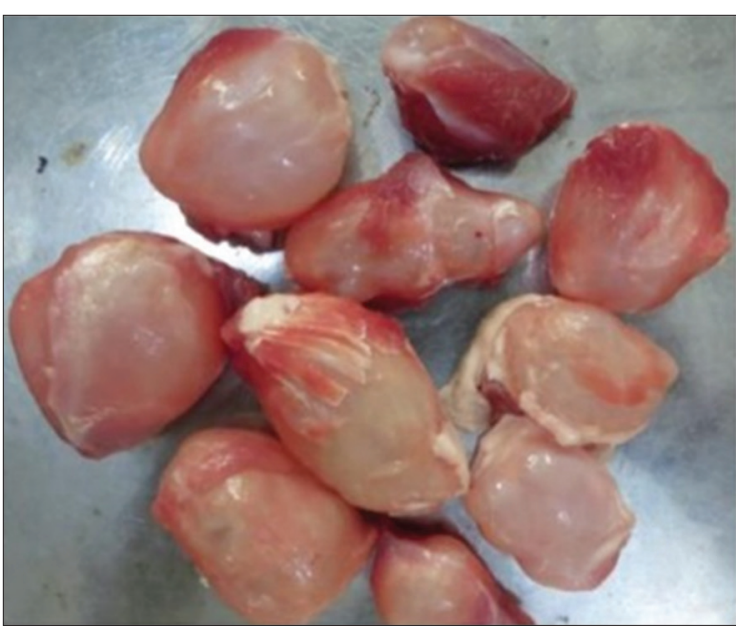

Figure-1: Collected cyst from thigh muscle.

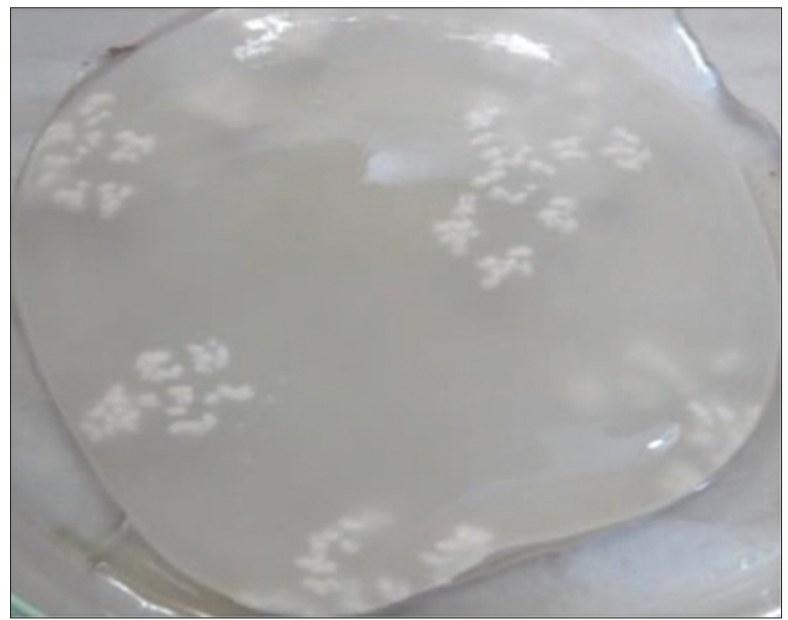

Figure-2: White clusters indicating a large number of scolices attached to the internal layer of cyst.

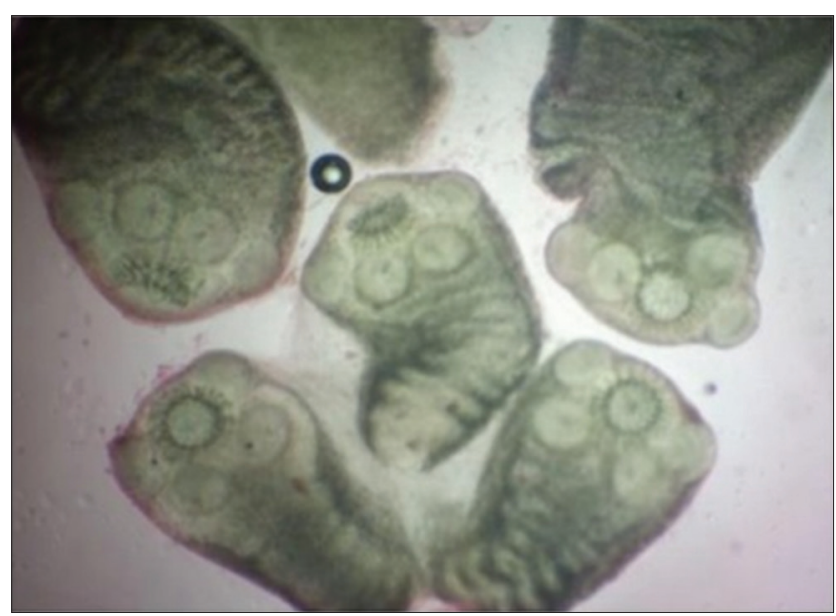

Figure-3: Larvae of Taenia multiceps multiple scolex $(10 \times)$.

\section{Discussion}

Coenurosis is an endemic disease of Bangladesh although very few studies have been conducted in this country and all of them are only epidemiological or case study [4]. The present study was carried to determine the prevalence of $T$. multiceps in goat

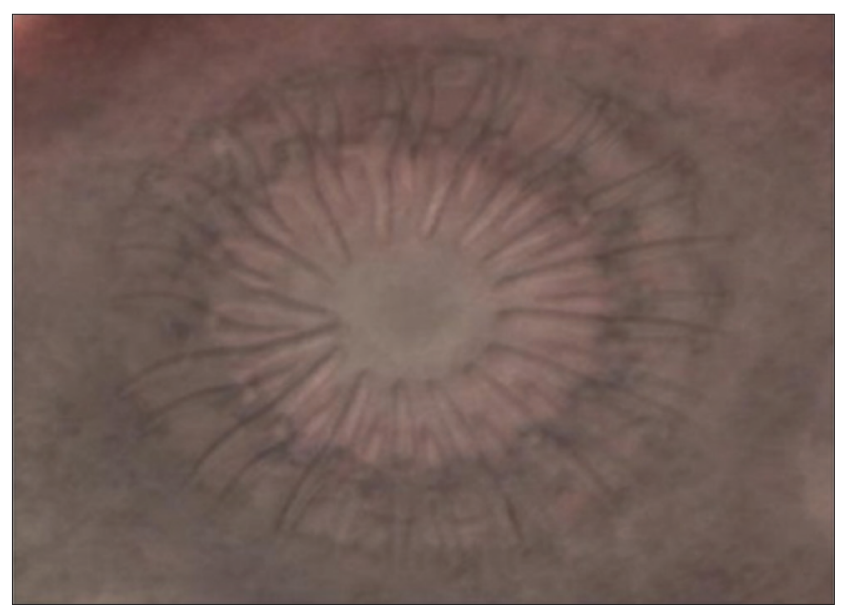

Figure-4: Double layer of rosteller hook.

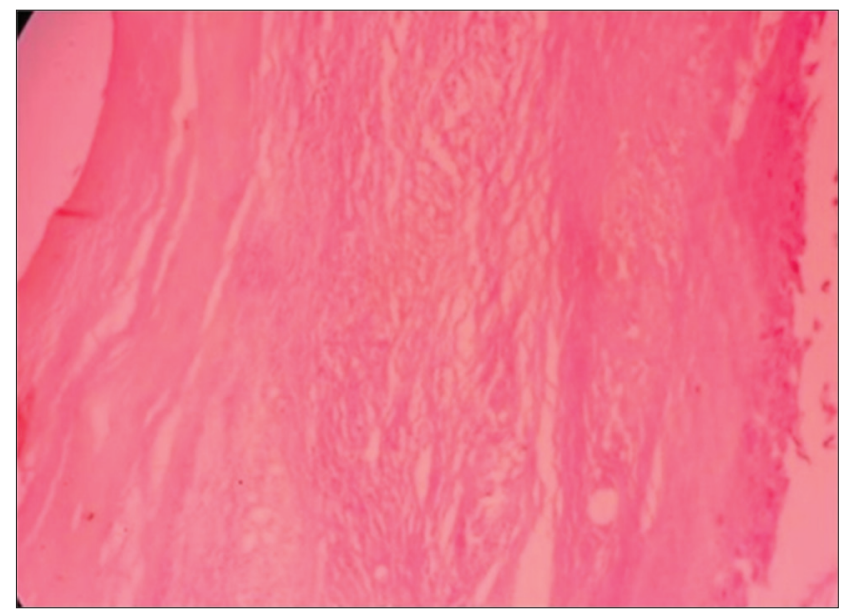

Figure-5: Thin layer of fibrous cyst walled and atrophy of adjacent muscle bundle.

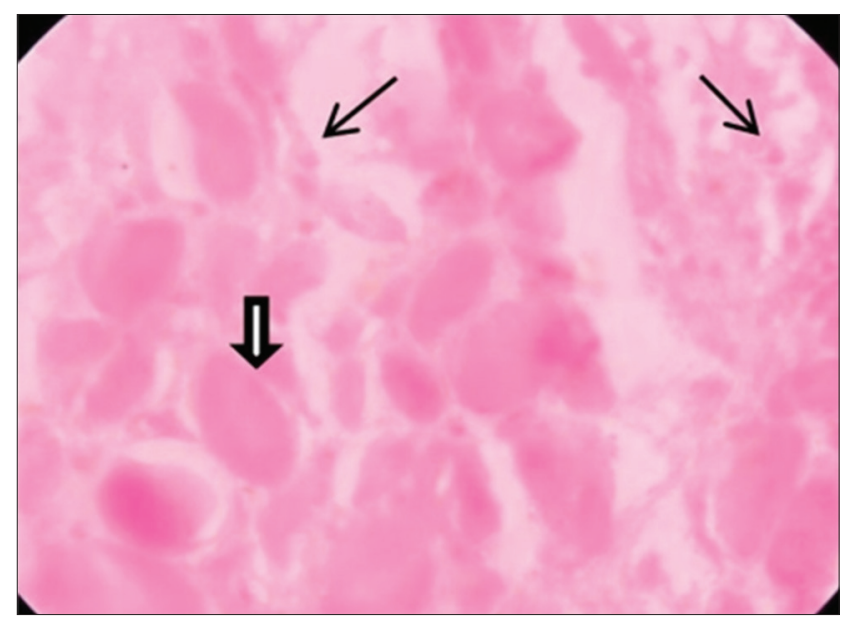

Figure-6: Infiltration of reactive cell (thin arrow) and Zenker's necrosis (thick arrow).

with their molecular detection and characterization. A total of 385 goats were examined postmortem, and $2.1 \%$ prevalence was recorded. All of the examined cysts were found in muscle and subcutaneous tissue of slaughtered goat. This is the first molecular study of the non-cerebral form of $T$. multiceps in goats in the country. Although the cerebral form of 
T. multiceps (C. cerebralis) in goats was reported in some area, 2.5\% at Patuakhali district [18] and 35 cases found in Mymensingh district during the period 2010-2011 [19]. Coenurosis in calves is also reported as $2.47 \%$ in Bangladesh [20]. In comparison with this study, C. cerebralis cyst is found in the thigh muscle [21] and subcutaneous tissue [22] of goat in Uttar Pradesh, India. In another study in Southern Iran, it is found that same parasite produced both cerebral and non-cerebral forms in sheep and goats [23]. In sheep, the common predilection sites of these parasites are the CNS. The coenurus cyst that occurred outside the CNS in goats was recorded as T. multiceps [2,24] or T. gaigeri [25]. Genetically, the cerebral cysts in sheep were identical with the non-cerebral cysts in goats [10]. Histopathological findings in the skeletal muscle infected with coenurus included degenerative and

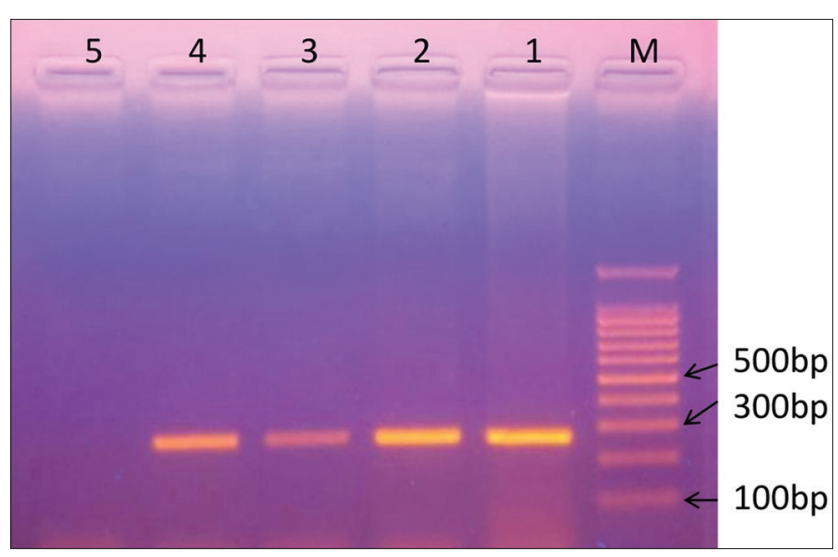

Figure-7: Agarose gel electrophoresis of polymerase chain reaction amplified $270 \mathrm{bp}$ amplicons of $12 \mathrm{~S}$ rRNA gene fragments. The Lane M indicates 100 bp ladder; S1-S4 positive sample; and S5 negative DNA sample. necrotic changes, hyalinization, and myositis which are in agreement with other research $[11,26]$.

Although coenurosis particularly in cerebral form in goat was reported in different area of Bangladesh, the molecular identification of T. multiceps was not done yet. Previously reported studies in other countries were based on amplification of several genes such as $12 \mathrm{~S}$ rRNA gene, cox1 gene, and nad 1 gene. We used only $12 \mathrm{~S}$ rRNA gene marker. The present molecular genetic approach was employed to characterize the DNA sequence of the non-cerebral metacestodal stage of T. multiceps and compared it with other available data from other countries. Goat non-cerebral thigh muscle cyst isolated sequences of this study were aligned with Greece sheep and goat, Iranian sheep, and complete $12 \mathrm{~S}$ rRNA gene of China.

\section{Conclusions}

This study showed that non-cerebral cyst is prevalent in this country which is very important for public health concern. This study depicts an idea of the non-cerebral form of zoonotic T. multiceps cyst which will be helpful in taenia cyst control and prevention.

\section{Authors' Contributions}

Research work was done by MOF and partly MSI. Research design was carried out by AMAMZS, MAH, and SC. All the authors participated in data analysis, while MM, AR, and MSI revised the manuscript. All authors read and approved the final manuscript.

\section{Acknowledgments}

The authors are thankful to HEQEP-CP: 3220 project for funding and Clinical Pathology Laboratory

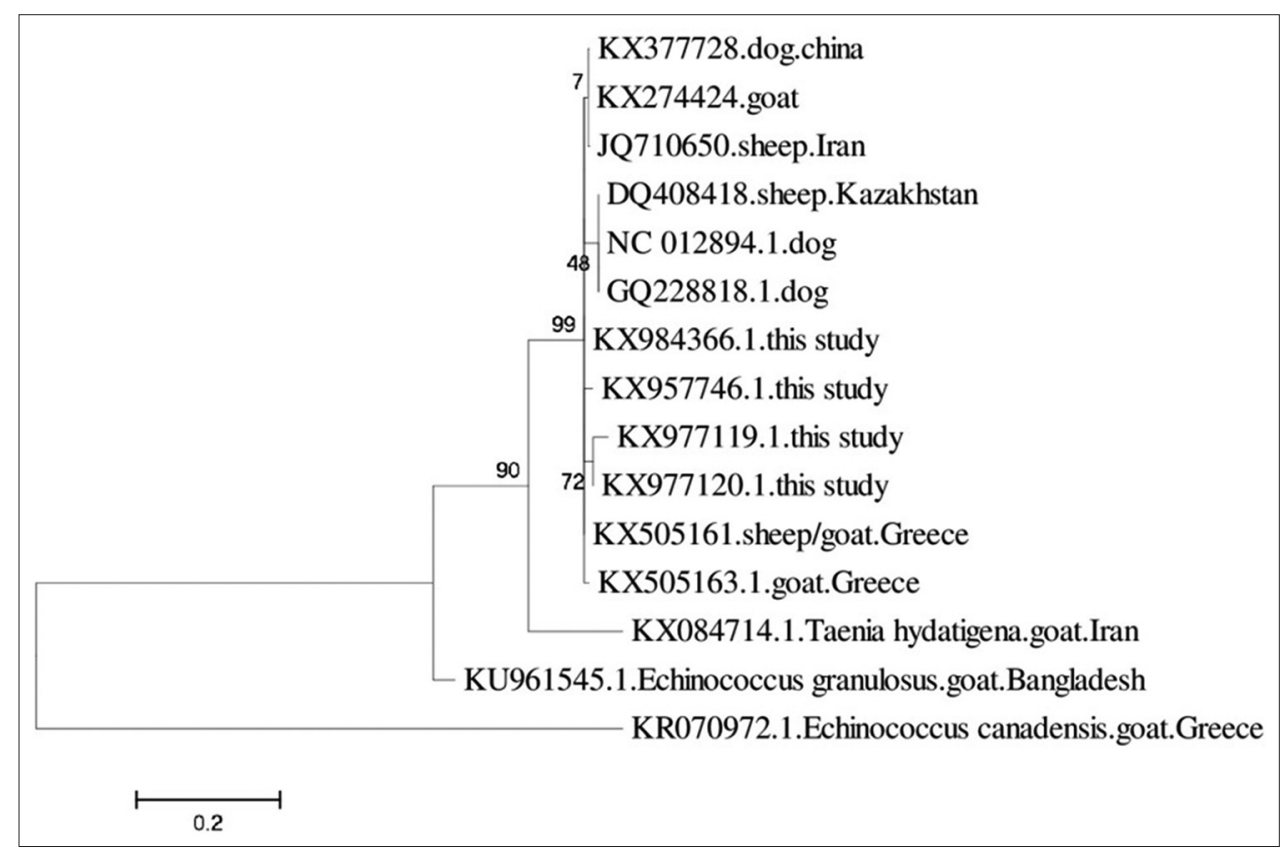

Figure-8: Phenogram constructed for the Taenia multiceps isolates of Chittagong, Bangladesh, and reference sequence with complete mitochondrial 12S rRNA gene sequence (GQ228818) using maximum likelihood method at 1500 bootstrap values. Echinococcus spp. and Taenia hydatigena were drawn as an outer group. 
of the Department of Pathology and Parasitology in Chittagong Veterinary and Animal Sciences University, for providing necessary research facility.

\section{Competing Interests} interests.

The authors declare that they have no competing

\section{References}

1. Christodoulopoulos, G., Theodoropoulos, G. and Petrakos, G. (2008) Epidemiological survey of cestode-larva disease in Greek sheep flocks. Vet. Parasitol., 153(3): 368-373.

2. Oge, H., Oge, S., Gonenc, B., Ozbakis, G. and Asti, C. (2012) Coenurosis in the lumbar region of a goat: A case report. Vet. Med. Czech., 57(6): 308-313.

3. Scala, A. and Varcasia, A. (2006) Updates on morphology, epidemiology and molecular characterization of coenurosis in sheep. Parasitogia, 48: 61-63.

4. Hossain, S.S., Amin, M.R. and Islam, A.B.M. (1999) Goat production and its breeding strategy in Bangladesh. In: Proceedings of the First National Workshop on Animal Breeding, BAU, Mymensingh. p17-36.

5. Nooruddin, M., Rashid, M.H. and Hashim, M.A. (2000) Extraneuralcoenuriasis in Bengal goats: Epidemiology. Prog. Agric., 11(1-2): 141-145.

6. Karim, M.R., Parvin, M.S., Hossain, M.Z., Islam, M.T. and Hussan, M.T. (2014) A report on clinical prevalence of diseases and disorders in cattle and goats at the Upazilla Veterinary Hospital, Mohammadpur, Magura. Bangladesh J. Vet. Med., 12(1): 47-53.

7. Rashid, M.H., Nooruddin, M. and Hashim, M.A. (2000) Extra neural coenuriasis in Bengal goats: 2 . Clinical propaedeutics progress. Agricultural, 11(1-2): 147-152.

8. Varcasia, A., Tanda, B., Giobbe, M., Solinas, C., Pipia, A.P., Malgor, R., Carmona, C., Garippa, G. and Scala, A. (2011) Cystic echinococcosis in Sardinia: Farmer's knowledge and dog infection in sheep farms. Vet. Parasitol., 181(2-4): 335-340.

9. Varcasia, A., Jia, W.Z., Yanb, H.B., Manunta, M.L., Pipia, A.P., Garippa, G., Scala, A. and Schuster, R.K. (2012) Molecular characterization of subcutaneous and muscular coenurosis of goats in United Arab Emirates. Vet. Parasitol., 190: 604-607.

10. Amrabadi, O., Oryan, A., Moazeni, M., Sharifiyazdi, H. and Akbari, M. (2015) Comparison of cerebral and non-cerebral coenurosis by genetic markers of glycolytic enzyme (enolase) and mitochondrial sequences in sheep and goats. Vet. Parasitol., 214: 333-336.

11. Oryan, A., Nazifi, S., Sharifiyazdi, H. and Ahmadnia, S. (2010) Pathological, molecular, and biochemical characterization of Coenurus gaigeri in Iranian native goats. $J$. Parasitol., 96: 961-967.

12. Oryan, A., Akbari, M., Moazeni, M. and Amrabadi, O.R. (2014) Cerebral and non-cerebral coenurosis in small ruminants. Trop. Biomed., 31(1): 1-16.

13. Christodoulopoulos, G., Dinkel, A., Romig, T., Ebi, D.,
Mackenstedt, U. and Loos-Frank, B. (2016) Cerebral and non-cerebral coenurosis: On the genotypic and phenotypic diversity of Taenia multiceps. Parasitol. Res., 115: 4543-4558.

14. Faruk, M.O., Siddiki, A.M.A., Karim, M.F., Masuduzzaman, M., Chowdhury, S., Islam, M.S. and Hossain, M. (2017) Molecular characterization of Echinococcus granulosus through amplification of $12 \mathrm{~S}$ rRNA gene and cox1 gene fragments from cattle in Chittagong, Bangladesh. World Acad. Sci. Eng. Technol. Int. Sci. Int. J. Biol. Biomol. Agric. Food Biotechnol. Eng., 11(4): 301-305.

15. Tamura, K., Stecher, G., Peterson, D., Filipski, A. and Kumar, S. (2013) MEGA6: Molecular evolutionary genetics analysis version 6.0. Mol. Biol. Evol., 30: 2725-2729.

16. Faruk, M.O., Siddiki, A.M.A., Masuduzzaman, M., Chowdhury, S. and Hossain, M.A. (2017) Identification and molecular characterization of Echinococcus granulosus from domestic goat in Chittagong, Bangladesh. Trop. Biomed., 34(4). (In Press).

17. Luna, L.G. (1968) Manual of Histologic Staining Methods of the Armed Forces Institute of Pathology. McGraw-Hill Book Company, Blakiston Division, New York. p94-95.

18. Rahman, M.A., Islam, M.A., Rahman, M.A., Talukder, A.K., Parvin, M.S. and Islam, M.T. (2012) Clinical diseases of ruminants recorded at the Patuakhali science and technology university veterinary clinic. Bangladesh J. Vet. Med., 10(1-2): 63-73.

19. Amin, M.N., Hashim, M.A., Hossain, M.A. and Al-Sultan, II. (2013) Coenurus cerebralis infection (Gid disease) in Black Bengal goats; effects on certain blood values after surgical treatment. J. Adv. Biomed. Pathobiol. Res., 3(1): 1-7.

20. İslam, A.W.M. and Rahman, M.S. (1997) A report on incidence of gid of calves of Bangladesh. Indian J. Anim. Health, 36: 187-188.

21. Madhu, D.N., Mahan, T., Sudhakar, N.R., Maurya, P.S., Banerjee, P.S., Sahu, S. and Pawde, A.M. (2014) Coenurus gaigeri cyst in the thigh of a goat and its successful management. J. Parasit. Dis., 38(3): 286-288.

22. Sharma, D. and Chauhan, P. (2006) Coenurosis status in Afro-Asian region: A review. Small Rumin. Res., 64: 197-202.

23. Akbari, M., Moazeni, M., Oryan, A., Sharifiyazdi, H. and Amrabadi, O. (2015) Experimental cerebral and non-cerebral coenurosis in goats: A comparative study on the morphological and molecular characteristics of the parasite. Vet. Parasitol., 211: 201-207.

24. Sharma, D.K., Sanil, N.K., Agnihofri, M.K. and Singh, N. (1995) Subcutaneous coenurosis in Barabari goat. Indian Vet. J., 72: 1203-1205.

25. Moghaddar, N. (2007) Occurrence of Coenurus gaigeri infection in goats in Shiraz, Iran. J. Appl. Anim. Res., 31(1): 83-84.

26. Kheirandish, R., Sami, M., Azizi, S. and Mirzaei, M. (2012) Prevalence, predilection sites and pathological findings of Taenia multiceps coenuri in slaughtered goats from southeast Iran. Onderstepoort. J. Vet. Res., 79(1): 436-441.

\section{$* * * * * * * *$}

